\title{
ENSINO DE EMPREENDEDORISMO NOS CURSOS PRESENCIAIS DE GRADUAÇÃO EM ADMINISTRAÇÃO EM FORTALEZA: UM ESTUDO DOS CONTEÚdos E InSTRUMENTOS PEDAgógicos
}

\author{
TEACHING ENTREPRENEURSHIP IN CAMPUS-BASED \\ UNDERGRADUATE ADMINISTRATION COURSES IN FORTALEZA: A STUDY \\ OF THE PEDAGOGIC CONTENT AND TOOLS
}

\begin{abstract}
Estevão Lima de CaRvalho Rocha (estevao.lcr@gmail.com) Gino Augusto BACCHI

Diego de Sousa Guerra

ESTÉLIO MENEZES RôLA JÚNIOR

Daniel Rodriguez de Carvalho Pinheiro

UNIVERSIDADE ESTADUAL DO CEARÁ
\end{abstract}

\section{RESUMO}

Esta pesquisa propõe a discussão acerca dos conteúdos e as estratégias de ensino de empreendedorismo em Instituições de Ensino Superior (IES) na cidade de Fortaleza. O empreendedorismo é um fenômeno associado à economia e ao comportamento humano (FILLION, 1999b), especialmente ao comportamento inovador (CARLAND; CARLAND, 2009). A discussão da capacidade empreendedora nata ou não ao ente humano suscitou a seguinte indagação: a oferta da disciplina de empreendedorismo utilizando-se de metodologias de ensino convencionais, em cursos de graduação em administração, contempla as prerrogativas pedagógicas para a formação do empreendedor? Os métodos são os próprios da pesquisa documental. O recorte temporal foi o primeiro semestre de 2010. Os resultados apontam para o fato de que na fase inicial, uma considerável parcela das IES pesquisadas não contemplou o ensino de empreendedorismo em seus projetos pedagógicos de curso. Entre as que contemplaram, verificou-se um predomínio das técnicas de ensino baseadas nas tradicionais exposições dos conteúdos. Portanto, nas instituições estudadas, o processo de ensino não foca a formação do empreendedorismo como téchnê. O foco é a informação e não a formação.

Palavras-chave: ensino do empreendedorismo; cursos de Administração. pesquisa documental; conteúdos; instrumentos pedagógicos. 


\section{ABSTRACT}

This study proposes a discussion of the content and strategies used for teaching entrepreneurship in Higher Education Institutions (HEI), in the city of Fortaleza. Entrepreneurship is a phenomenon associated with the economy and human behavior (FILLION, 1999b), especially innovative behavior (CARLAND; CARLAND, 2009). The debate over whether entrepreneurship can be considered an innate ability has raised the following question: does the conventionally taught entrepreneurship offered as part of undergraduate courses in administration take into account the teaching prerogatives required in the education of an entrepreneur? The methods are themselves in search of documentary sources. The time frame was the first half of 2010. The results point to the fact that in the initial phase, a significant number of the HEIs surveyed did not include the teaching of entrepreneurship when planning their courses. Among those that did, there is a predominance for teaching techniques based on traditional content exhibition. Therefore, in the institutions studied, the teaching process does not focus on the formation of entrepreneurship as téchnê. The focus is on information rather than training.

Keywords: entrepreneurship education; administration courses, business schools; documentary research; content; teaching tools.

\section{INTRODUÇÃO}

O empreendedorismo é um fenômeno econômico-comportamental. Cronologicamente, a abordagem econômica prevalece como o pano de fundo para as primeiras interpretações, subsidiando, dessa forma, os primeiros estudos sobre o tema (FILLION, 1999c). No entendimento desses autores, o empreendedorismo tinha como maior força motriz a economia, interpretada como a forma de se obter lucros com base no aproveitamento de oportunidades, assumindo os riscos dessa decisão. Não ignoravam, porém, que o campo do empreendedorismo vai além da economia, envolvendo, também, criação, desenvolvimento e gerenciamento de negócios.

A relação do empreendedorismo com a economia e os negócios desperta interesse de estudos no tema devido à influência perante o desenvolvimento econômico e social das nações (ou regiões). Schumpeter 
(1984) é um dos primeiros a enfatizar a importância dos empresários capitalistas (rigorosamente ele não usa a palavra francesa empreendedores) para o processo de desenvolvimento econômico.

Essa atividade empreendedora ele chamou de destruição criadora (SCHUMPETER, 1984). Criadora porque dava origem a negócios e à geração de empregos, fundamentando parte da essência inovadora e de mudança que envolve o ato de empreender, ao utilizar a expressão destruição criativa. $\mathrm{O}$ autor considera, ainda, a inovação como a mola propulsora da criação de novos produtos, novos mercados e novas concepções de produção, tudo isso, atuando de forma direta no desenvolvimento da economia capitalista.

A vertente comportamental tomou corpo baseada nos estudos das motivações e das principais características dos empreendedores (FILLION, 1999b; SOUZA; GUIMARÃES, 2006). Nesse sentido, diversas publicações apresentaram as principais características do empreendedor, o que possibilitou construir-se um perfil do empreendedor (SCHMIDT; BOHNENBERGER, 2009). É com base neste corpo teórico que se pode desenhar o caminho para o ensino do empreendedorismo, que tem a tarefa histórica de fazer a formação do sujeito empreendedor, disposta em características e conhecimentos específicos pertinentes ao negócio.

Fillion (1999a) afirma que o empreendedorismo pode ser ensinado, condicionando-se, entretanto, sua efetiva aprendizagem às metodologias específicas para a formação do empreendedor. Levantando a discussão quanto à capacidade empreendedora ser inata ou não ao ente humano, suscita-se a seguinte indagação, que é colocada baseada na associação da aprendizagem à metodologia: a oferta da disciplina de empreendedorismo, utilizando-se de metodologias de ensino convencionais, em cursos de graduação em administração, contempla as prerrogativas pedagógicas para a formação do empreendedor?

O objetivo do artigo é analisar os conteúdos, as metodologias e os recursos pedagógicos de disciplinas de empreendedorismo. A fim de alcançar tal objetivo foram realizados os cruzamentos entre os objetivos pedagógicos, propostos por Dornelas (2008); métodos e técnicas do Projeto de Ensino Universitário de Empreendedorismo (PEUE) e os recursos didáticos de ensino de empreendedorismo do PEUE versus a frequência com que se apresentam nos cursos pesquisados. 


\section{REFERENCIAL TEÓRICO}

O ambiente econômico gerado pela cultura empreendedora produz riqueza e contribui para a melhoria da qualidade de vida das pessoas (ANGELO, 2003; FILLION, 1999b, MILLER et al., 2009). A significativa presença das micro e pequenas empresas (MPE) no Produto Interno Bruto (PIB) e na oferta de empregos conduzem para o reconhecimento do relevante papel do empreendedor como agente social do desenvolvimento e gerador de riquezas (FERREIRA; RAMOS; GIMENEZ, 2006; GATICA; ARRIAGADA; RUSQUE, 2006).

A relação do empreendedorismo com a economia e abertura de novos negócios tem sido constante desde os estudos seminais sobre o tema. Trabalhos como os dos economistas Richard Cantillon e JeanBaptiste Say (publicados, respectivamente, em 1755 e 1816) já mostravam interesse nesse aspecto, contudo, envolvendo nesse campo de estudo o gerenciamento e desenvolvimento dos negócios criados (FILLION, 1999b).

Uma das formas de interpretar o ato empreendedor considera a inovação como a fonte geradora desse movimento. Schumpeter (1984) registra que o viés inovador do empreendedor contribui para o surgimento de novos produtos e novos processos de gestão. Essa abordagem dos três últimos autores considera a perspectiva econômica como premissa para estudar e interpretar o fenômeno do empreendedorismo (FERREIRA; RAMOS; GIMENEZ, 2006).

Outra forma de abordar o empreendedorismo é o comportamento empreendedor (FERREIRA; MATTOS, 2003; LEITÃO, CRUZ, 2006; MACIEL, 2009). Fillion (1999c) identifica em seus estudos um sistema de valores elementares que explicam este comportamento. E os empreendedores são pessoas independentes, líderes e com certa autoridade formal respaldada pelo sucesso do negócio.

McClelland (1961) apresenta um estudo sobre o comportamento empreendedor que pode ser considerado um referencial para esse campo do conhecimento. Este autor relaciona a necessidade de realização como uma das primeiras características associada ao empreendedor (MARTENS, FREITAS, 2008).

Desse confronto de juízos, entre economistas e comportamentalistas estudiosos do empreendedorismo, surgiram pesquisas que procuram explicar as características que, associadas ao ambiente socioeconômico, fazem com que o indivíduo encampe a iniciativa de abrir novos negócios ou aplique formas inéditas de produção 
e gestão aos negócios, com os respectivos riscos da tomada de decisão. Diversos autores têm contribuído com estudos que tentam identificar essas características. Com base nessas características, estudos são produzidos a fim de se delinear um perfil apropriado para o sujeito empreendedor, como afirmam Markman e Baron (2003) e Gomes (2004).

\section{PERFIL EMPREENDEDOR}

A identificação de traços característicos de personalidade e comportamento empreendedores tem sido a linha de estudo adotada por pesquisadores como a tentativa de estabelecer parâmetros que se apresentam de forma constante em empreendedores a fim de se chegar a um perfil desses sujeitos (SANTOS et al., 2008). Schumpeter (1984) pondera, entretanto, para a discordância dos pesquisadores quanto à definição do sujeito empreendedor, alertando que diversos estudos consideram da mesma forma uma pessoa que criou um negócio e aquela que apenas gerencia uma empresa. Nesse sentido, Fillion (1999c) relata que, enquanto empreendedores criam o negócio com base em uma visão e tendem a iniciar um processo de desenvolvimento, os gerentes ou operadores compram um negócio e procuram ganhar a vida por meio do bom uso de suas habilidades operacionais.

Isto posto, muitas pesquisas têm sido realizadas com base na perspectiva que aborda a compreensão das características da pessoa empreendedora em função do processo de empreender. Este processo diz respeito às funções, atividades e atitudes associadas à percepção de oportunidades, que levam à criação de novos negócios, que tratam de forma organizada a busca por essas oportunidades (ANGELO, 2003; SCHMIDT; BOHNENBERGER, 2009). Diversas características são encontradas na literatura apresentando certa convergência na definição do perfil empreendedor (ANGELO, 2003; FILLION, 1999b; SOUZA; GUIMARÃES, 2006). O Quadro 1 apresenta uma compilação de características indicadas pelos respectivos autores como componentes do perfil do empreendedor. 
Quadro 1: Matriz de características de empreendedor e empreendedorismo

\begin{tabular}{|c|c|c|}
\hline Autor & Carac & erísticas \\
\hline $\begin{array}{l}\text { Ângelo } \\
\text { (2003) }\end{array}$ & $\begin{array}{l}\text { 1.Criatividade e inovação } \\
\text { 2. Habilidade ao aplicar a } \\
\text { criatividade } \\
\text { 3. Força de vontade e fé }\end{array}$ & $\begin{array}{l}\text { 4. Foco na geração de valor } \\
\text { 5. Correr riscos }\end{array}$ \\
\hline $\begin{array}{c}\text { Dolabela } \\
(2008)\end{array}$ & $\begin{array}{l}\text { 1. Perseverança } \\
\text { 2. Iniciativa } \\
\text { 3. Criatividade } \\
\text { 4. Protagonismo } \\
\text { 5. Energia } \\
\text { 6. Rebeldia de padrões } \\
\text { 7. Capacidade de diferenciar-se } \\
\text { 8. Comprometimento }\end{array}$ & $\begin{array}{l}\text { 9. Capacidade incomum de } \\
\text { trabalho } \\
\text { 10. Liderança } \\
\text { 11. Orientação para o futuro } \\
\text { 12. Imaginação } \\
\text { 13. Proatividade } \\
\text { 14. Tolerância a riscos moderados } \\
\text { 15. Alta tolerância à ambiguidade } \\
\text { e incerteza. }\end{array}$ \\
\hline $\begin{array}{c}\text { Dornelas } \\
(2008)\end{array}$ & $\begin{array}{l}\text { 1. Visionários } \\
\text { 2. Sabem tomar decisões } \\
\text { 3. Agregam valor ao que fazem } \\
\text { 4. Exploram ao máximo as } \\
\text { oportunidades } \\
\text { 5. Determinados e dinâmicos } \\
\text { 6. Dedicados } \\
\text { 7. Otimistas } \\
\text { 8. Independentes }\end{array}$ & $\begin{array}{l}\text { 9. Geram riqueza } \\
\text { 10. Líderes e formadores de } \\
\text { opinião } \\
\text { 11. Bem relacionados } \\
\text { 12. Organizados } \\
\text { 13. Planejadores } \\
\text { 14. Abertos ao conhecimento } \\
\text { 15. Assumem riscos calculados } \\
\text { 16. Criam valor para a sociedade }\end{array}$ \\
\hline $\begin{array}{c}\text { Schmidt e } \\
\text { Bohnenberger } \\
\text { (2009) }\end{array}$ & $\begin{array}{l}\text { 1. Autoeficaz } \\
\text { 2. Assume riscos calculados } \\
\text { 3. Planejador } \\
\text { 4. Detecta oportunidades }\end{array}$ & $\begin{array}{l}\text { 5. Persistente } \\
\text { 6. Sociável } \\
\text { 7. Inovador } \\
\text { 8. Líder }\end{array}$ \\
\hline
\end{tabular}

Fonte: Adaptado de Ângelo (2003); Dolabela (2008); Dornelas (2008); Schmidt; Bohnenberger (2009).

A relevância da definição do perfil empreendedor está associada ao fato de criar-se referência para o desenvolvimento de processos que contribuam para a formação de empreendedores, utilizando tais características como premissa pedagógica. Segundo Dornelas (2008, p. 23):

Até alguns anos atrás, acreditava-se que o empreendedorismo era inato, que o empreendedor nascia com um diferencial e era predestinado ao sucesso nos negócios. Pessoas sem essas características eram desencorajadas a empreender.

Ao contrário disso, no campo atual de estudo do empreendedorismo existe uma quebra desse paradigma, que aponta para a 
perspectiva da formação empreendedora com base em métodos adaptados que contemplem as idiossincrasias do empreendedor (CUNHA; STEINER NETO, 2005; FILLION, 1999b; SANTOS et al., 2008; SOUZA; GUIMARÃES, 2006), uma vez que o sistema educacional desempenha papel primordial no processo de previsão e desenvolvimento dos traços empresarias (LEE; LIM; PATHANK, 2006).

\section{ENSINO DO EMPREENDEDORISMO}

Um dos caminhos introdutórios do ensino de empreendedorismo nas Universidades está relacionado ao curso criado pela escola de Administração de Harvard, em 1947, visando qualificar ex-combatentes de guerra para a abertura de pequenos negócios. No Brasil, um dos primeiros atos baseou-se na introdução de uma disciplina em um curso de Especialização em Administração, em São Paulo, pela Escola de Administração da Fundação Getúlio Vargas (FGV), em 1981. Em 1984, a proposta foi estendida para o curso de graduação em administração da FGV-SP (DOLABELA, 2008; GUIMARÃES, 2003). Deste período em diante, o ensino de empreendedorismo tem se expandido para vários Cursos de Graduação em Administração por todo o País (MARTENS; FREITAS, 2008; SOUZA; GUIMARÃES, 2006).

A dificuldade da inserção no mercado de trabalho tem suscitado nas Instituições de Ensino Superior (IES) a crescente preocupação em formar profissionais que não dependam, somente, de vínculo empregatício para se sustentar e aplicar seus conhecimentos. A esse fato, tem se associado a dificuldade da sobrevivência profissional em uma sociedade de elevada competitividade (SOUZA; GUIMARÃES, 2006). Nessa linha, Dolabela (2008) compreende que uma economia movida, essencialmente, pelo Estado e por grandes empresas tende a direcionar as IES para a formação de empregados, a fim de atuar nestes dois segmentos. Para o autor, este modelo tem sido esgotado na proporção que a alteração das relações de trabalho e de produção tem deslocado seu eixo para as pequenas empresas, impulsionando a sociedade a formar empregadores em maior número.

Diversos estudos relatam o desenvolvimento da formação empreendedora por meio da educação, desde o ensino médio até o superior (MARTENS; FREITAS, 2008; FERREIRA; RAMOS; GIMENEZ, 2006; VIEIRA; RIBEIRO; MELATTI, 2009; FILLION, 1999b; CARVALHO; ZUANAZZI， 2003; GUIMARÃES， 2003; CUNHA; STEINER NETO, 2005; DAVID et al., 2001). Especificamente 
para o ensino superior, os autores registram que as IES têm inserido em suas matrizes curriculares disciplinas relacionadas ao tema do empreendedorismo, porém, em particular nos cursos de administração, têm sido encontradas certas ambiguidades quanto à diferenciação entre a formação do administrador tradicional e o empreendedor (FERREIRA; RAMOS; GIMENEZ, 2006).

Tradicionalmente, os cursos de administração têm concentrado mais atenção na formação de profissionais para atuar gerenciando grandes empresas (VIEIRA; RIBEIRO; MELATTI, 2009). A mudança deste paradigma tem sido uma vertente nos estudos do ensino do empreendedorismo nas IES. $\mathrm{O}$ enfoque educacional do empreendedorismo tende a ser direcionado para os processos de inovação, criação e desenvolvimento de empresas em vez da clássica educação em negócios para gerenciar uma empresa (MARTENS; FREITAS, 2008).

Autores como Paço et al. (2011) defendem a tese de que a educação clássica está enraizada nos preceitos básicos da educação tradicional, fazendo com que a previsibilidade, planejamento e estabilidade na sala de aula limitem a criatividade e o comportamento dos estudantes. Nessa esteira, ratificam a importância da proposição de metodologias alternativas que aumentem a propensão dos alunos para empreender (OOSTERBEEK; VAN PRAAG; IJSSELSTEIN, 2007; NECK; GREENE, 2011).

A busca de equilíbrio entre o modelo de formação tradicional com outro de mais aplicações práticas, que valorize a formação das habilidades e competências empreendedoras, tem sido uma tendência crescente no processo de ensino-aprendizagem do empreendedorismo (FERREIRA; MATTOS, 2003; SOUZA; GUIMARÃES, 2006; LOPES, 2008). As escolas europeias têm se destacado pelo desenvolvimento de inúmeras estratégias pedagógicas para abordagens inovadoras nos últimos anos (GASSE; TREMBLAY, 2006), enquanto as escolas estadunidenses e brasileiras, apesar de apresentarem relevantes avanços na temática, continuam a adotar os tradicionais métodos pedagógicos (SOLOMON; DUFFY; TARABISHY, 2002; FERREIRA; RAMOS; GIMENEZ, 2006).

Singh (1990) ratifica essa posição em dois momentos: quando afirma que a educação tradicional constitui uma barreira para o empreendedorismo, e quando sugere a iminente necessidade de avaliação e reordenação do sistema de ensino para que se cultive a cultura empreendedora.

Dornelas (2008) preconiza que um curso voltado para o empreendedorismo deveria centrar-se em objetivos que proporcionassem 
ao estudante uma formação alinhada com a amplitude dos aspectos relacionados ao campo do empreendedorismo. No Quadro 2 são relacionados os objetivos pedagógicos apontados pelo autor. Nesse sentido, os conteúdos programáticos das disciplinas de empreendedorismo deveriam apresentar temas que remetessem ao estudo e ensino dos objetivos pedagógicos propostos pelo autor.

Quadro 2: Objetivos do ensino do empreendedorismo nas IES

\begin{tabular}{cl}
\hline 1 & Identificação e entendimento das habilidades do empreendedor \\
\hline 2 & Identificação e análise de oportunidades \\
\hline 3 & Como ocorre a inovação e o processo empreendedor \\
\hline 4 & Importância de empreendedorismo para o desenvolvimento econômico \\
\hline 5 & Como preparar e utilizar um plano de negócios \\
\hline 6 & Como identificar fontes e obter financiamento para o novo negócio \\
\hline 7 & Como gerenciar e fazer a empresa crescer \\
\hline
\end{tabular}

Fonte: Adaptado de Dornelas (2008, p. 23-24).

\section{O ensino do empreendedorismo nos cursos de Administração}

Segundo Souza e Guimarães (2006), o ensino do empreendedorismo já é praticado por diversas IES, sobretudo nos cursos de administração. Entre as principais bases de referências adotadas por estas IES, para a inclusão do ensino de empreendedorismo, está o Projeto de Ensino Universitário de Empreendedorismo (PEUE), desenvolvido pelo Instituto Euvaldo Lodi (IEL) e o Serviço Brasileiro de Apoio à Micro e Pequena Empresa (SEBRAE). Por meio desses projetos, as instituições inseriram procedimentos relacionados à cultura e ao ensino do empreendedorismo. No entanto, para Souza e Guimarães (2006), a falta de dados sistematizados sobre os conteúdos as metodologias e os resultados pedagógicos e práticos desenvolvidos impede a elaboração de uma agenda que repasse uma formatação melhor estruturada para o desenvolvimento de ensino desse tema.

Em face dessa ausência de dados, estes autores realizaram uma pesquisa em parceria com o IEL e a Universidade de Brasília (UnB), obtendo informações sobre a atuação dessas IES em relação ao ensino do empreendedorismo.

Entre as 131 instituições pesquisadas foram consolidadas informações que diz respeito aos métodos e técnicas de ensino, assim como aos recursos didáticos utilizados. Os primeiros estão apresentados no Quadro 3, os segundos no Quadro 4. 
Quadro 3: Métodos e técnicas de ensino de empreendedorismo utilizados nas IES

\begin{tabular}{lc}
\hline Métodos e técnicas de ensino de empreendedorismo & Quantidade de IES \\
\hline 1. Exercícios & 85 \\
\hline 2. Aulas expositivas & 84 \\
\hline 3. Recomendações de leitura & 83 \\
\hline 4. Depoimentos de empreendedores & 82 \\
\hline 5. Teoria aplicada à realidade dos participantes & 75 \\
\hline 6. Casos & 73 \\
\hline 7. Jogos & 57 \\
\hline 8. Teatro popular & 13 \\
\hline
\end{tabular}

Fonte: Souza e Guimarães (2006, p. 211).

Em relação aos dados do Quadro 3, Souza e Guimarães (2006, p. 211) afirmam que: "a teoria aplicada à realidade dos participantes, estudos de casos e jogos, que são técnicas recomendadas para o ensino do empreendedorismo, não aparecem com a frequência esperada." O que se percebe é maior tendência de aplicação dos métodos pedagógicos tradicionais, tais quais, aula expositiva e exercícios.

Quadro 4: Recursos didáticos de ensino de empreendedorismo mais utilizados nas IES

\begin{tabular}{lc}
\hline Recursos didáticos de ensino de empreendedorismo & Quantidade de IES \\
\hline 1. Tempestade de ideias & 80 \\
\hline 2. Livro O segredo de Luísa & 76 \\
\hline 3. Pesquisa de mercado & 75 \\
\hline 4. Exercícios de criatividade & 73 \\
\hline 5. Elaboração de casos & 71 \\
\hline 6. Concluir a elaboração de plano de negócios & 71 \\
\hline 7. Entrevista com empreendedor & 71 \\
\hline 8. Apresentação do plano de negócios & 71 \\
\hline 9. Avaliação do aprendizado & 69 \\
\hline 10. Desenvolver a visão gerencial da empresa & 64 \\
\hline
\end{tabular}

Fonte: Souza e Guimarães (2006, p. 212).

Os recursos didáticos constantes do Quadro 4 foram sugeridos na Oficina do Empreendedor, metodologia adotada no PEUE, conforme explicam os pesquisadores, que destacam a tempestade de ideias, o livro O segredo de Luísa e a pesquisa de mercado entre os recursos mais utilizados pelas IES.

Após esta revisão, vale ressaltar, a importância que tais concepções trazem das novas percepções por parte das IES, no sentido de formar o discente capaz de gerir seu próprio negócio e não apenas ser um 
colaborador dentro de uma corporação. De maneira geral, vários modelos pedagógicos são adotados por IES interessadas em formar o estudante com as principais características do empreendedor. Diante deste cenário, foi realizado um estudo comparativo sobre as disciplinas de empreendedorismo, com seus conteúdos, métodos e recursos pedagógicos apresentados pelos cursos de graduação em administração, modalidade presencial, de 20 IES localizadas em Fortaleza, em relação às propostas pedagógicas apresentadas nos Quadros 2, 3 e 4.

\section{MetOdOLOGIA}

Para a classificação desta pesquisa são utilizados os critérios descritos por Vergara (2009). Dessa forma, esta pesquisa pode ser classificada como qualitativa e documental. Foram considerados como unidades de análise os Cursos de Graduação em Administração da cidade de Fortaleza, capital do Estado do Ceará, pelo papel relevante que esta cidade tem como centro de formação profissional superior e por concentrar grande parte da atividade econômica do Estado.

No levantamento inicial sobre as IES, utilizaram-se os documentos disponíveis no sistema e-MEC, do Ministério da Educação, que oferece uma lista de instituições de ensino superior e cursos cadastrados. Com base nessa consulta, verificou-se a existência de 32 instituições, 20 na modalidade presencial e 12 na modalidade à distância, que oferecem regularmente o curso de graduação em Administração.

Após a definição das unidades de análise, foram consultadas as matrizes curriculares de cada curso para que se identificassem aquelas que têm a disciplina Empreendedorismo e, posteriormente, foi feito o contato via telefone ou correio eletrônico, entre os meses de março e abril de 2010, para levantar dados como a modalidade de ensino, o programa da disciplina e os recursos utilizados. Para o levantamento destas informações, foram analisados os planos de ensino de cada disciplina, fornecidos por cada uma das instituições, por meio da técnica documental de coleta de dados, viabilizada pela utilização de instrumento do tipo check-list.

Entre as 32 instituições avaliadas, 21 apresentavam a disciplina de empreendedorismo na matriz curricular, sendo 12 cursos na modalidade presencial e nove na modalidade à distância. Por questões de acessibilidade, as instituições na modalidade à distância foram excluídas da análise. As respostas comumente obtidas por meio do contato eram 
que todas as informações relacionadas ao curso poderiam ser acessadas por intermédio do sítio eletrônico da instituição, o que não foi observado.

Já, em relação aos cursos presenciais, todas as instituições responderam à solicitação. Dessa maneira, as unidades de análise da pesquisa passaram a ser os cursos presenciais de Administração, na cidade de Fortaleza, que contavam com a disciplina de empreendedorismo na matriz curricular. Informações sobre o porte e a natureza das instituições podem ser observadas na Tabela 4.

Tabela 4: Caracterização das instituições pesquisadas

\begin{tabular}{lcl}
\hline Instituição & $\begin{array}{c}\text { Tipo de } \\
\text { instituição }\end{array}$ & Número de alunos \\
\hline Universidade de Fortaleza & Privada & 2000 ou mais \\
\hline Estácio/FIC & Privada & 2000 ou mais \\
\hline Faculdade Nordeste & Privada & Entre 800 e 2000 \\
\hline Faculdade Christus & Privada & Entre 800 e 2000 \\
\hline Faculdade Integrada da Grande Fortaleza & Privada & Entre 800 e 2000 \\
\hline Faculdade Farias Brito & Privada & Entre 800 e 2000 \\
\hline Faculdade Sete de Setembro & Privada & Entre 800 e 2000 \\
\hline Faculdade Cearense & Privada & Entre 800 e 2000 \\
\hline Instituto Ceará de Ensino e Cultura & Privada & Até 800 \\
\hline Faculdade Metropolitana da Grande Fortaleza & Privada & Até 800 \\
\hline Faculdade Evolutivo & Privada & Até 800 \\
\hline Instituto de ensino superior do Ceará & Privada & Até 800 \\
\hline
\end{tabular}

Em seguida, para aqueles cursos que ofertavam a disciplina e foram coletadas informações suficientes para o processo de pesquisa, realizou-se um procedimento analítico-teórico constando da comparação entre os conteúdos, métodos e recursos pedagógicos inseridos nos respectivos programas destas disciplinas com as recomendações dos pesquisadores para o processo de ensino-aprendizagem do empreendedorismo (DOLABELA, 2008; DORNELAS, 2008; FILLION, 1999a). Também são apresentadas tabelas com os resultados encontrados e considerações sobre o panorama do ensino do empreendedorismo nas instituições analisadas.

\section{ReSUlTAdOS E DiscuSSÃo}

Do de 32 cursos de graduação em administração encontrados em Fortaleza, 20 são da modalidade de ensino presencial e 12 de ensino à distância (EAD). Dos 20 cursos presenciais, 12 apresentam em suas matrizes curriculares a disciplina de empreendedorismo. Como o objetivo de estudo é levantar dados sobre o ensino de empreendedorismo, os 
demais cursos presenciais não tiveram seus dados analisados. Em relação às instituições pesquisadas, para o percentual encontrado de $60 \%$ entre os cursos de administração que apresentam a referida disciplina pode-se supor que o ensino e a cultura de empreendedorismo carecem de maiores divulgações na região em que se encontram as IES.

Das 12 disciplinas de empreendedorismo dos respectivos cursos de administração foram coletados dados dos programas de ensino das disciplinas, em que foram considerados os conteúdos programáticos para a análise comparativa entre os objetivos pedagógicos da disciplina e os sugeridos pelo Quadro 2. Para a análise comparativa entre as sugestões dos métodos, técnicas e recursos pedagógicos do PEUE dos Quadros 3 e 4 foram considerados as metodologias e recursos pedagógicos descritos nos mesmos programas. Cada item dos Quadros 2, 3 e 4 foi analisado isoladamente em função das informações encontradas nos programas das disciplinas.

$\mathrm{Na}$ análise dos conteúdos das disciplinas foi adotada a proposta temática de objetivos pedagógicos indicados por Dornelas (2008). Os resultados apresentados na Tabela 1 demonstram certa deficiência no tema gerenciamento da empresa, o que não condiz com a formação empreendedora. Segundo Fillion (1999c), os empreendedores devem aprender a gerenciar como forma de garantir a sobrevivência da empresa em função dos ciclos das atividades dos negócios. Em relação à abordagem específica da temática da inovação e do processo empreendedor na disciplina, as análises foram prejudicadas devido à ausência de informações claras sobre a existência dessa discussão nos documentos avaliados. Entretanto, a frequência deste e dos demais temas é detalhada na Tabela 1.

Tabela 1: Objetivos pedagógicos versus Frequência nas disciplinas

\begin{tabular}{lcc}
\hline \multicolumn{1}{c}{ Objetivos pedagógicos } & $\begin{array}{c}\text { Frequência nas } \\
\text { disciplinas }\end{array}$ & $\%$ \\
\hline $\begin{array}{l}\text { 1. Identificação e entendimento das habilidades } \\
\text { do empreendedor }\end{array}$ & 12 & 100 \\
\hline 2. Identificação e análise de oportunidades & 12 & 100 \\
\hline $\begin{array}{l}\text { 3. Como ocorre a inovação e o processo } \\
\text { empreendedor }\end{array}$ & 9 & 75,0 \\
\hline $\begin{array}{l}\text { 4. Importância de empreendedorismo para o } \\
\text { desenvolvimento econômico }\end{array}$ & 8 & 66,6 \\
\hline $\begin{array}{l}\text { 5. Como preparar e utilizar um plano de negócios } \\
\text { 6. Como identificar fontes e obter financiamento } \\
\text { para o novo negócio }\end{array}$ & 7 & 12 \\
\hline 7. Como gerenciar e fazer a empresa crescer & 2 & 100,3 \\
\hline
\end{tabular}


O procedimento seguinte das análises consistiu em verificar a descrição dos métodos e técnicas de ensino adotadas pelas IES para desenvolver o processo de ensino-aprendizagem do empreendedorismo. As análises foram realizadas em função dos oito itens propostos no Quadro 3. O resultado apresenta semelhança ao encontrado por Souza e Guimarães (2006), porém com maior acentuação nos itens 1 e 2. O enfoque maior reservado às aulas expositivas e aos exercícios demonstra a tendência detectada por estes autores quanto à aplicação de métodos tradicionais para o ensino do empreendedorismo nas IES. A Tabela 2 apresenta a frequência com que os métodos e técnicas são distribuídos entre as disciplinas de empreendedorismo das IES selecionadas.

Tabela 2: Métodos e técnicas do PEUE versus Frequência nas disciplinas

\begin{tabular}{lcc}
\hline Métodos e técnicas do PEUE & $\begin{array}{c}\text { Frequência nas } \\
\text { Disciplinas }\end{array}$ & $\%$ \\
\hline 1. Exercícios & 11 & 91,6 \\
\hline 2. Aulas expositivas & 12 & 100 \\
\hline 3. Recomendações de leitura & 7 & 58,3 \\
\hline 4. Depoimentos de empreendedores & 7 & 58,3 \\
\hline 5. Teoria aplicada à realidade dos participantes & 8 & 66,6 \\
\hline 6. Casos & 5 & 41,6 \\
\hline 7. Jogos & 2 & 16,6 \\
\hline 8. Teatro popular & 0 & 0 \\
\hline
\end{tabular}

Para a análise dos recursos didáticos foi adotado procedimento semelhante ao anterior. Os itens do Quadro 4 foram tomados como referência para a constatação da frequência desses recursos didáticos nos programas das disciplinas. Desses dados, é possível perceber que a tempestade de ideias é tida como o recurso didático mais explorado. Embora exista certa limitação pelo reduzido detalhamento na descrição nos programas das disciplinas, pode-se conjecturar que desse recurso preponderante derivam outros que aparecem em maior frequência, como os exercícios de criatividade a elaboração e conclusão de planos de negócios. Na Tabela 3 estão os resultados encontrados para a frequência dos recursos didáticos inseridos nos programas das disciplinas de empreendedorismo das IES pesquisadas.

A baixa frequência dos itens $3,7,8$ e 10 demonstra certa dissonância com as recomendações para o processo de ensinoaprendizagem apontado pelo PEUE (SOUZA; GUIMARÃES, 2006). A entrevista com o empreendedor é indicada por Dolabela (2008) como uma etapa relevante no processo educacional, pois possibilita a percepção de certas características pertinentes ao sujeito empreendedor. A avaliação do 
aprendizado apresenta-se com a frequência máxima, porém esta se processa, em sua maioria, sob a forma tradicional de avaliação, por meio de testes e trabalhos teóricos.

A utilização de método tradicional de avaliação pode levar a um comprometimento nos resultados da aprendizagem. Autores têm registrado que no processo educacional do empreendedor é recomendada a avaliação do desenvolvimento das habilidades dos alunos que se evidenciam na aplicação prática dos conhecimentos (OOSTERBEEK; VAN PRAAG; IJSSELSTEIN, 2007; NECK; GREENE, 2011).

Tabela 3: Recursos didáticos de ensino de empreendedorismo do PEUE versus Frequência nas disciplinas

\begin{tabular}{lcc}
\hline $\begin{array}{l}\text { Recursos didáticos de ensino de } \\
\text { empreendedorismo do PEUE }\end{array}$ & $\begin{array}{c}\text { Frequência nas } \\
\text { disciplinas }\end{array}$ & $\%$ \\
\hline 1. Tempestade de ideias & 11 & 91,6 \\
\hline 2. Livro O segredo de Luísa & 4 & 33,3 \\
\hline 3. Pesquisa de mercado & 2 & 16,6 \\
\hline 4. Exercícios de criatividade & 7 & 58,3 \\
\hline 5. Elaboração de casos & 6 & 50,0 \\
\hline 6. Concluir a elaboração de plano de negócios & 8 & 66,6 \\
\hline 7. Entrevista com empreendedor & 2 & 16,6 \\
\hline 8. Apresentação do plano de negócios & 2 & 16,6 \\
\hline 9. Avaliação do aprendizado & 12 & 100 \\
\hline 10. Desenvolver a visão gerencial da empresa & 3 & 25,0 \\
\hline
\end{tabular}

A utilização de método tradicional de avaliação pode levar a um comprometimento nos resultados da aprendizagem. Autores têm registrado que no processo educacional do empreendedor é recomendada a avaliação do desenvolvimento das habilidades dos alunos que se evidenciam na aplicação prática dos conhecimentos (OOSTERBEEK; VAN PRAAG; IJSSELSTEIN, 2007; NECK; GREENE, 2011).

\section{CONSIDERAÇõES FINAIS}

Essa pesquisa teve como objetivo analisar a proposta pedagógica apresentada em disciplinas de empreendedorismo, em cursos presenciais de graduação em administração, e verificar a presença de conteúdos e estratégias de ensino normalmente utilizados e recomendados no processo de ensino-aprendizagem de empreendedorismo em IES brasileiras.

$\mathrm{Na}$ fase inicial, o estudo revela que uma considerável parcela das IES pesquisadas não contemplou o ensino de empreendedorismo em seus projetos pedagógicos. Entre as que contemplaram, verificou-se que existe 
predomínio da aplicação dos processos tradicionais de ensino, contrariando as propostas mais indicadas para o desenvolvimento do ensino e aprendizagem do empreendedorismo. No que compete aos conteúdos, observou-se a presença uniforme em todas as disciplinas sobre os temas das habilidades do empreendedor e o estudo de oportunidades. Estas, juntamente com o plano de negócios foram as temáticas mais destacadas nos conteúdos programáticos. Por outro lado, o tema gerenciamento e crescimento da empresa, pouco apareceu. A presença irregular dos temas pode ser interpretada como efeito da falta de melhor compreensão da abrangência do ser empreendedor. Esta envolve, além da capacidade de criar novos negócios com base em oportunidades percebidas, mantê-los e fazê-los crescer.

Para os métodos e recursos didáticos verificados nas disciplinas pesquisadas observou-se maior presença de atividades teóricas, em que o locus sala de aula parece ser excessivamente explorado. No sentido oposto, as atividades pedagógicas que se relacionam com aulas práticas obtiveram baixa frequência nos programas das disciplinas. É importante destacar que a formação empreendedora preconiza métodos, técnicas e recursos que possibilitem o ensino das habilidades essenciais do empreendedor. $\mathrm{O}$ uso de atividades práticas que vão além da sala de aula pode permitir melhores resultados no processo de ensino-aprendizagem dessas habilidades.

Este trabalho responde, em boa medida, a pergunta de partida. A aula expositiva não forma uma alma empreendedora. Essa alma depende da inovação. Inovação precisa ser experimentada. A prática valida a inovação. Depois, os resultados do estudo indicam uma formação incompleta do sujeito empreendedor ao se prevalecer aulas e recursos de elevada predominância da informação sobre a formação (paideía), entendida como práxis empreendedora. Para o estudante de Administração, o empreendedorismo deveria ser uma atividade formadora e não informativa.

É importante salientar que o ensino do empreendedorismo é um campo relativamente novo no meio acadêmico, o que implica na carência de docentes plenamente capacitados para atuar nessa área. Além disso, a falta de maior discernimento entre a formação do empreendedor e o gerente-proprietário pode induzir a certa similaridade nos métodos pedagógicos aplicados.

Os resultados deste estudo têm implicações gerenciais e acadêmicas para as IES, pois a melhor compreensão da estrutura pedagógica da disciplina de empreendedorismo pode subsidiar o 
aperfeiçoamento do seu planejamento. Ademais, o conceito de empreendedorismo, na medida em que evolui e aumenta sua percepção por meio de pesquisas, tende a se tornar um guia relevante para a elaboração de conteúdos e práticas nas IES. Pela natureza documental da pesquisa, os resultados não levam a uma conclusão definitiva. Alguns aspectos que dizem respeito ao desenvolvimento da metodologia pedagógica aplicada pelas IES carecem de melhor entendimento. A falta de detalhamento descritivo nos programas pesquisados impede que se chegue a uma conclusão sobre a forma e local da aplicação dos recursos pedagógicos.

Sob esse prisma, sugere-se a realização de pesquisa com professores e coordenadores dos cursos pesquisados, a fim de se coletarem informações que complementem o presente estudo. Sugere-se ainda detectar qual a percepção da influência de um modelo pedagógico mais apropriado para o ensino do empreendedorismo, em função da formação das características do empreendedor. Também poderiam ser estudadas as instalações que possibilitariam melhor desenvolvimento do ensino de empreendedorismo, pois o processo pedagógico dessa aprendizagem implica as dinâmicas das práticas e vivências.

Os cursos à distância poderiam ser estudados mais sistematicamente, porque têm crescente importância na educação brasileira. Os resultados dessas pesquisas serão úteis tanto para processo de aperfeiçoamento e consolidação desta tipologia de ensino quanto para a prospecção e validação de novas metodologias abordadas neste contexto, que poderão ser aplicadas para aperfeiçoar o aprendizado nos cursos convencionais.

\section{REFERÊNCIAS}

ÂNGELO, E. B. Empreendedorismo: a revolução do novo Brasil. Revista de Economia \& Relações Internacionais, v. 1, n. 2, p. 37-48, 2003.

CARLAND, J. A.; CARLAND, J. Innovation: the soul of entrepreneurship. Small Business Institute National Proceedings, v. 33, n. 1, p. 173-184, 2009.

CARVALHO, C.E.; ZUANAZZI, J. Análise das características de alunos de graduação em Administração e sua relação com as expectativas do ensino de empreendedorismo. In: EGEPE - ENCONTRO DE ESTUDOS SOBRE EMPREENDEDORISMO E GESTÃO DE PEQUENAS 
EMPRESAS. 3., 2003, Brasília. Anais... Brasília: UEM/UEL/UnB, 2003, p. $125-141$.

CUNHA, R.A.; STEINER NETO, P.J. Desenvolvendo Empreendedores: o desafio da Universidade do século XXI. In. SEMINÁRIO LATINOIBÉRICO DE GESTIÓN TECNOLÓGICA, 11., 2005, Salvador. Anais ... Salvador.

DAVID, D. E.H.; ROVEDA, M.V.; REVIDO, R.B.; GAUTHIER, F.A. O.; COLOSSI, N.; FRANZONI, A.M. Aspectos pedagógicos no ensino do empreendedorismo. In: ENCONTRO NACIONAL DE EMPREENDEDORISMO, 3., 2001, Florianópolis. Anais..., Florianópolis, 2001.

DOLABELA, F. Oficina do empreendedor. Rio de Janeiro: Sextante, 2008.

DORNELAS, J.C.A. Empreendedorismo: transformando ideias em negócios. 3.ed. Rio de Janeiro: Elsevier, 2008.

FERREIRA, J. M.; RAMOS, S.C.; GIMENEZ, F.A.P. Estudos comparativos das práticas didático-pedagógicas do ensino de empreendedorismo em universidades brasileiras e norte-americanas. Revista Alcance, v. 13, n.2, p. 207- 225, 2006.

FERREIRA, P. G.G.; MATTOS, P. L. C. L. Empreendedorismo e Práticas Didáticas nos Cursos de Graduação em Administração: os Estudantes Levantam o Problema. In: ENCONTRO DA ASSOCIAÇÃO NACIONAL DE PÓS-GRADUAÇÃO EM ADMINISTRAÇÃO, 27., 2003, Rio de Janeiro. Anais... Rio de Janeiro, 2003.

FILLION, L. J. Diferenças entre sistemas gerenciais de empreendedores e operadores de pequenos negócios. Revista de Administração de Empresas, v. 39. n. 4, p. 06-20, 1999b.

FILLION, L. J. O empreendedorismo como tema de estudos superiores. Brasília: Seminário: A Universidade formando gestores, 1999a.

FILLION, L.J. Empreendedorismo: empreendedores e proprietáriosgerentes de pequenos negócios. Revista de Administração, v. 34, n. 2, p. 05-28, 1999c.

GASSE, Y.; TREMBLAY, M. Entrepreneurship education among students at a Canadian university: An extensive empirical study of students' entrepreneurial preferences and intentions. In: FAYOLLE, A; 
KLANDT, H (Eds.). International Entrepreneurship Education, Edward Elgar, Cheltenham, UK. 2006.

GATICA, C. C.; ARRIAGADA, R.A.; RUSQUE, A.M. Capacidad empreendedora y capital social. In. SOUZA; E.C.L.; GUIMARÃES, T. A. (Orgs.). Empreendedorismo além do plano de negócios. São Paulo: Atlas, 2006.

GOMES, A. F. Perfil empreendedor de mulheres que conduzem seu próprio negócio: um estudo na cidade de vitória da conquista-BA. Revista Alcance, v. 11, n. 2, p.207-226, 2004.

GUIMARÃES, L.O. Empreendedorismo no currículo dos cursos de Administração: uma análise da organização didático-pedagógica. $E$ \& $G$ Economia e Gestão, v. 2 e 3, n. 4/ 5, p. 78-95, 2003.

LEE, S.; LIM, S.; PATHANK, R. Influences on students attitudes toward entrepreneurship: a multi-country study. Internacional Entrepreneurship and Manage Journal, v. 2, n.3, p. 351-366, 2006.

LEITÃO, F. A.; CRUZ, N. M. Los rasgos psicológicos del emprendedor y la continuidad del proyecto emrpesarial: un estudio empírico de los emprendedores brasileños. Revista Eletrônica de Administração, v. 12, n. 2, 2006.

LOPES, S.L. Competências empreendedoras: um estudo no setor de tecnologia da informação. Biguaçu, 2008. Dissertação (Mestrado em Administração) - Faculdade de Administração, Universidade Vale do Itajaí.

MACIEL, C.O. Comportamento empreendedor e capacidades organizacionais: hierarquização e mensuração de seus efeitos no desempenho de empresas de pequeno porte. Revista Alcance, v. 16, n.1, p. 26-44, 2009.

MARKMAN, G. D.; BARON, R. A. Person-entrepreneurship fit: why some people are more successful as entrepreneurs than others. Human Resource Management Review, v.13, n.2, p.281-301, 2003.

MARTENS, C.D.P.; FREITAS, H. Influência do ensino de empreendedorismo nas intenções de direcionamento profissional dos estudantes. Estudo \& Debate, v. 15, n.1, p. 71-95, 2008.

McCLELLAND, D.C. The achieving society. New Jersey: Van Nostrand, 1961. Disponível em: 
<http://www.questia.com/PM.qst?a=o\&d=10299666>. Acesso em: 17/01/2011.

MILLER B.; BELL, J.; PALMER, M.; GONZALEZ, A.; PETROLEUM, P. Predictors of entrepreneurial intentions: a quasi-experiment comparing students enrolled in introductory management and entrepreneurship classes. Journal of Business Entrepreneurship, v.2, n.21, p. 39-62, 2009.

NECK, H. M.; GREENE, P. G. Entrepreneurship Education: Known Worlds and New Frontiers. Journal of Small Business Management, v. 49, n.1, p. 55-70, 2011.

OOSTERBEEK, H.; VAN PRAAG, M.; IJSSELSTEIN, A. The Impact of Entrepreneurship Education on Entrepreneurship Competencies and Intentions: An Evaluation of the Junior Achievement Student MiniCompany Program. Jena Economic Research Papers, n. 2008-027, 2007.

PAÇO, A. M. F; FERREIRA, J.M.; RAPOSO, M. RODRIGUES, R. G.; DINIS, A. Behaviours and entrepreneurial intention: Empirical findings about secondary students. Journal of Internacional Entrepreneurship, v.1, n.9, p. 1-19, 2011.

SANTOS, S. A.; DANTAS, A. B.; SANTOS, P. C. F.; SILVA, M. A.; Propensão empreendedora em alunos de administração da UFAL: uma análise comparativa com estudantes das modalidades presencial e a distância. In: CONGRESSO LATINOAMERICANO Y DEL CARIBE SOBRE EL ESPÍRITU EMPRESARIAL 23., 2008, Florianópolis. Anais... Florianópolis: ICESI/UFSC, 2008.

SCHMIDT, S.; BOHNENBERGER, M. C. Perfil Empreendedor e Desempenho Organizacional. Revista de Administração Contemporânea, v. 13, n. 3, p. 450-467, 2009.

SCHUMPETER, J. A. Teoria do desenvolvimento econômico. São Paulo: Fundo de Cultura, 1984.

SINGH, J.B. Entrepreneurship education as a catalyst of development in the third world. Journal of Small Business and Entrepreneurship, v. 7, n. 4, p. 56-63, 1990.

SOLOMON, G.T, DUFFY, S., TARABISHY, A. The state of entrepreneurship education in the United States: a nationwide survey and analysis. Internacional Journal of Entrepreneuship, v. 1, n. 1, p. 65-87, 2002. 
SOUZA; E.C.L.; GUIMARÃES, T.A. O ensino do empreendedorismo em instituições de ensino superior brasileiras. In: SOUZA, E.C.L.; GUIMARÃES, T.A. Empreendedorismo além do plano de negócios. São Paulo: Atlas, 2006.

VERGARA, S.C. Projetos e relatórios de pesquisa em Administração. 10.ed. São Paulo: Atlas, 2009.

VIEIRA, S.F.A.; RIBEIRO, P.R.; MELATTI, G.A. O ensino de empreendedorismo nos Cursos de Graduação em Administração: um estudo comparativo entre duas Universidades Estaduais do Paraná. In: SEMINÁRIOS EM ADMINISTRAÇÃO, 12., 2009, São Paulo. Anais... São Paulo: USP, 2009. 
DAdOS DOS AUTORES

ESTeVão Lima de CaRvalho Rocha (estevao.lcr@gmail.com)

Mestrando em Administração pela UECE

Instituição de vinculação: Universidade Estadual do Ceará

Fortaleza/CE - Brasil

Áreas de interesse em pesquisa: Empreendedorismo em pequenos e médios negócios.

GinO AuguSTO BACCHI (g.bacchi@uol.com.br)

Mestre em Administração pela UECE

Instituição de vinculação: Faculdade Evolutivo

Fortaleza/CE - Brasil

Áreas de interesse em pesquisa: Gestão de pessoas, sofrimento no trabalho e Ensino de Administração.

DiEGo DE SOUSA GUERRA (diegoguerra@gmail.com)

Mestre em Administração pela UECE

Instituição de vinculação: Universidade Estadual do Ceará

Fortaleza/CE - Brasil

Áreas de interesse em pesquisa: Marketing e Sociedade, Pesquisa Transformativa do Consumidor, e Ensino e Pesquisa em Administração.

ESTÉLIO MENEZES RôLA JÚNIOR (esteliomrj@gmail.com)

Mestrando em Administração pela UECE

Instituição de vinculação: Universidade Estadual do Ceará

Fortaleza/CE - Brasil

Áreas de interesse em pesquisa: Inovação, Sustentabilidade e Empreendedorismo.

Daniel Rodriguez de Carvalho Pinheiro (daniel.pinheiro@gmail.com) Doutor em Sociologia pela UFC

Instituição de vinculação: Universidade Estadual do Ceará (UECE)

Fortaleza/CE - Brasil

Áreas de interesse em pesquisa: Epistemologia, Empreendedorismo e Gestão da Inovação.

Recebido em: 21/02/2011 • Aprovado em: 17/06/2011 